\title{
FORMULATION AND CHARACTERIZATION OF BIODEGRADABLE CHITOSAN FILMS FOR TOPICAL APPLICATION OF TERBINAFINE HCI
}

S. M. Ahmed ${ }^{1}$, M. A. Ibrahim ${ }^{2}$, H. A. Sarhan ${ }^{3}$ and M. A. Amin ${ }^{2}$

${ }^{1}$ Department of Industrial Pharmacy, Faculty of Pharmacy, Assiut University, Assiut, Egypt

${ }^{2}$ Department of Pharmaceutics and Industrial Pharmacy, Faculty of Pharmacy, El-Azhar University, Assiut branch, Egypt

${ }^{3}$ Department of Pharmaceutics and Industrial Pharmacy, Faculty of Pharmacy, El-Minia University, El-Minia, Egypt

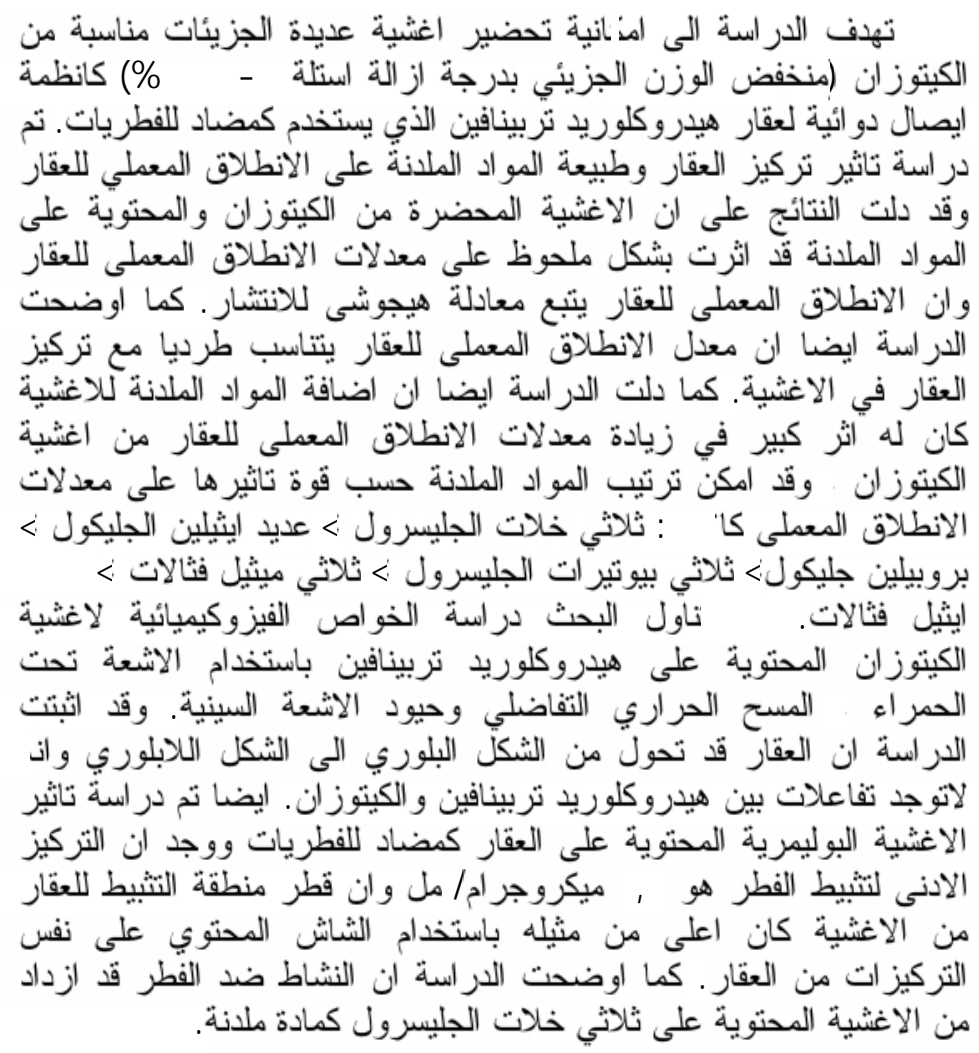


Chitosan biodegradable films containing terbinafine $\mathrm{HCl}$ (Tr.HCl) were evaluated for their potential drug delivery at a controlled rate. Terbinafine $\mathrm{HCl}$ could be loaded at $1.8 \% \mathrm{w} / \mathrm{w}$ of polymer in films, which were translucent and flexible. The effect of drug loading and nature of plasticizers on the in-vitro release of Tr. $\mathrm{HCl}$ have been examined. Physicochemical characterization of $\mathrm{Tr} . \mathrm{HCl}$ via thermal, spectroscopic, $\mathrm{X}$-ray diffraction, and scanning electron microscopy techniques revealed information on the solidstate properties of $\mathrm{Tr} . \mathrm{HCl}$ as well as chitosan in films. While chitosan was in an amorphous form, $\mathrm{Tr}$. $\mathrm{HCl}$ seemed to be present in crystalline form in the films. It was found that the release rate of the drug was directly proportional to drug concentraton. Also medicated chitosan films plasticized with water-soluble plasticizers as glycerol triacetate (GTA), propylene glycol (PG), and polyethylene glycol 400 (PEG 400), produced fast release in comparison with water insoluble plasticizers as glycerol tributyrate $(G T B)$, dimethyl phthalate (DMPH), and diethyl phthalate (DEPH). The characterizations of chitosan films conducted by $I R, X$-ray, and DSC, showed that no interaction occurred between Tr. $\mathrm{HCl}$ and chitosan polymer. The minimum inhibitory concentration (MIC) of the drug against candida albicans was investigated. Results showed that MIC of Tr. $\mathrm{HCl}$ was $1.4 \mu \mathrm{g} / \mathrm{ml}$. The inhibition zone diameter of Tr. $\mathrm{HCl}$ chitosan films was higher than that of $\mathrm{Tr} . \mathrm{HCl}$ normal dressing. Also antifungal activity of Tr.HCl was enhanced in plasticized chitosan films. The results were promising for topical formulation of Tr. $\mathrm{HCl}$ in biodegradable chitosan films and have the potential to be used as a novel drug delivery.

\section{INTRODUCTION}

In recent years, biodegradable polymeric system have gained importance for design of surgical devices, artifical organs, drug delivery systems with different routs of administrations, carriers of immobilized enzymes and cells, biosensors, ocular inserts, and materials for orthopedic applications ${ }^{1}$. These polymers are classified as either synthetic (polyesters, polyamides, polyanhydries) or natural (polyaminoacides, polysaccharides) $^{2}$. Polysaccharides-based polymers represent a major class of materials, which includes agarose, aligante, carageenan and chitosan. Chitosan, $\beta$ $(1,4)$ 2-amino-2-D-glucose, is a cationic biopolymer produced by alkaline N-deacetylation of chitin, which is the main component of the shells of crab, shrimp, and krill. Chitosan has found many applications, including tissue engineering, owing to its biocompatibility, low toxicity, and 
degradation in the body by enzymes such as chitosanase and lysozymes ${ }^{3}$, which has opened up avenues for modulating drug release in-vivo in the treatment of various diseases. These chitosan-based delivery systems range from microparticles to nanoparticles ${ }^{4}$, gels $^{5}$ and films ${ }^{6}$. Further, gels and films of chitosan have been used for oral delivery of chlorhexidine digluconate in the treatment of fungal infections ${ }^{7}$. In addition, chitosan has been extensively evaluated as a carrier of antineoplastic agents such as 5-flurouracial ${ }^{8}$, mitoxantrone ${ }^{9}$, cytarabine $^{10}$ and placlitaxel ${ }^{11}$.

The film forming property of chitosan has found many applications in tissue engineering and drug delivery by virtue of its mechanical strength and rather slow biodegradation $^{12}$. Some drug-loaded chitosan films are emerging as novel drug delivery systems ${ }^{13 \& 14}$, and films appear to have potential topical delivery of antifungal drugs.

Terbinafine $\mathrm{HCl}$ is a synthetic allylamine antifungal agent ${ }^{15}$. It can be administered orally as well as topical application. It is considered the agent of choice for treatment of dermatophyte nail infections ${ }^{15}$. The objective of this study was to develop a chitosan film loaded with certain concentrations of terbinafine $\mathrm{HCl}$. These films have been evaluated for the release of impregnated terbinafine $\mathrm{HCl}$, characterized by various physical techniques and microscopy, and examined for antifungal activity by zone of inhibition technique.

\section{MATERIALS AND METHODS}

\section{Materials}

Chitosan grades $\mathrm{L}^{*}$, degree of deacetylation (\%DD) 80-85\%, was purchased from Sigma-Aldrich company, Germany, Terbinafine $\mathrm{HCl}$ was gift sample from Novartias company (Cairo, Egypt), Absolute ethanol was purchased from March KgaA (Darmstadt, Germany), Acetic acid, potassium dihydrogen phosphate, sodium hydroxide, anhydrous calcium chloride, ammonium chloride and PEG 400 was obtained from El-Nasr Pharmaceutical Chemicals Co., (Egypt), Glycerol triacetate (GTA), Glycerol tributyrate (GTB), Diethyl phthalate (DEPH) and Dimethyl phthalate (DMPH) was obtained from Fluka Co., Germany, Silicon adhesive [Super Automotive and consumer products Co., (U.S.A.) Other solvents and chemicals were of analytical grade.

\section{Equipment}

Digital micrometer (Mitutoyo, Kanagawa, Japan); dissolution-test apparatus, SR11 6-flasks (Hanson research Co., USA), double beam spectrophotometer (Shimadzu, UV150-02, Shimadzu Co., Japan); pH meter (Ama digital, Ama Co., Germany); IR-Spectrophotometer, [Shimadzu Co., Japan]; Differential Scanning Calorimeter, DSC-50 equipped with computerized data station (Shimadzu Co., Japan); X-ray diffractometer [Phillips Co., Netherlands]., which is equipped with curved graphite crystal mono- 
chromater, automatic divergence slite and automatic controller PW/1710. The target used was $\mathrm{CuK} \alpha$ radiation operating at $40 \mathrm{Kv}$ and $30 \mathrm{~mA}(\lambda$ $\mathrm{Ka}=1.5418 \mathrm{~A})$. The system was calibrated using silicon disc and/or powder $\left(\mathrm{d}_{111}=3.1355\right.$ a) as an external standard. The diffraction pattern was achieved using continuous scan mode with $2 \theta^{\circ}$ ranging from $40^{\circ}$ to $60^{\circ}$. JEOL, scanning electron microscope [JSM5200, Japan].

\section{Methods \\ Film preparation}

The films were prepared using teflon plates as casting substrate (8 $\mathrm{cm}$ in diameter) by a casting solvent evaporation technique as follows: 2.5 $\mathrm{g}$ of chitosan was dissolved in $25 \mathrm{ml}$ aqueous acetic acid solution ( $1 \% \mathrm{v} / \mathrm{v})$ with a constant stirring for $48 \mathrm{hrs}$ to give chitosan solution. Different concentrations of terbinafine $\mathrm{HCl}(1$, $1.2, \quad 1.4, \quad 1.6$ and $1.8 \% \mathrm{w} / \mathrm{w}$ of polymer) with or without different types of plasticizers at $20 \% \mathrm{w} / \mathrm{w}$ of polymer (GTA, PG, PEG400, GTB, DMPH, and DEPH). The resultant solution was left to stand until all air bubbles disappeared, then $8.5 \mathrm{ml}$ of the bubble free liquid was poured into a circular teflon mold on dust-freeleveled surface, and left to dry at room temperature for $24 \mathrm{hrs}$. The dried films were evaluated within one week after their preparation ${ }^{16}$.

\section{Content uniformity of the films}

To ensure uniform distribution of Tr. $\mathrm{HCl}$ in the prepared films, a content uniformity test was performed in triplicate. Samples representing different regions within the film were cut and weighted, and terbinafine $\mathrm{HCl}$ was extracted with 1:1 solvent mixture of acetonitrile and ethanol $(\mathrm{v} / \mathrm{v})$ twice for $12 \mathrm{hrs}$ at room temperature. The extracts were collected and absorbance was measured at $265 \mathrm{~nm}$ against suitable blank, and the drug concentration was calculated.

\section{Film thickness}

The film thickness was determined at ten points of the film, using digital micrometer (Mitutoyo, Kanagawa, Japan), and the film thickness was recorded and found to be $22 \pm 0.2 \mu \mathrm{m}$.

\section{In-vitro release studies}

The release experiment was performed according to paddle method (JP x II) at a rotational speed of $50 \mathrm{rpm}$, which was the optimum speed to prevent film rupture. The release medium was $400 \mathrm{ml}$ of phosphate buffer $\quad(\mathrm{pH}=6.8)$ equilibrated at $37^{\circ} \mathrm{C} \pm 0.5^{\circ} \mathrm{C}$. It was taken into consideration that the used buffer volume kept sink conditions during the experiment. To avoid water evaporation, the vessels were covered with an aluminum foil during the experiments. The film was carefully pressed into the bottom of the glass vessel by the aid of silicon adhesive. At time intervals $0.25,0.5$, $1.0,1.5,2.0,3.0,4.0,5.0$ and $6.0 \mathrm{hrs}$, $5 \mathrm{ml}$ sample was withdrawn and replaced by an equal volume of fresh 
release medium previously equilibrated at $37^{\circ} \mathrm{C}$. The amount of drug released $(\mathrm{mg})$ was measured spectrophoto-metrically at $\lambda_{\max } 265$ $\mathrm{nm}$ and plotted as a function of time.

A cumulative correction was made for the previously removed samples in determining the total amount released according to the following formula ${ }^{17}$ :

$C_{n}=C_{n}$ meas $+5 / 400 \Sigma C_{s}^{n-1}$ meas

Where:

$C_{n}$ meas $=$ spectrophotometrically measured concentration,

$C_{n}=$ concentration of the $\mathrm{n}^{\text {th }}$ sampling expected in the receiving medium if previous samples had not been removed,

$n-1=$ total volume of all samples removed prior to a sample being measured, and

$C s=$ total of all spectrophotometrically measured concentrations at n-1 samples.

\section{Solid-state characterizations}

To study the molecular properties of terbinafine $\mathrm{HCl}$ and chitosan, the solid-state characterization was done by the application of thermal, infrared, and X-ray diffraction. During these studies, solid-sate characteristics of the drug and chitosan were compared with those of the film to reveal any changes occurring as a result of film preparation.

\section{Infrared spectroscopy (IR)}

Infrared spectroscopy spectra of untreated Tr.HCl, the polymer (chitosan L*; \%DD 80-85), casted film of the drug with the polymer and its corresponding physical mixture were done by using at a range of $4000-400 \mathrm{~cm}^{-2}$. Potassium bromide (KBr) disk method was used for powder samples. The samples were ground, mixed thoroughly with $\mathrm{KBr}$ and compressed at a pressure of 6 ton $/ \mathrm{cm}^{2}$ using IR compression machine. Chitosan films were directly used during the test.

\section{Differential scanning calorimetry (DSC)}

Differential Scanning Calorimetry thermograms were carried out on untreated $\mathrm{Tr} . \mathrm{HCl}$, the polymer (chitosan L*; \%DD 80-85), casted film of the drug with the polymer and its corresponding physical mixture The procedure involved heating an accurately weighed sample $(5 \mathrm{mg})$ encapsulated in an aluminum pan at a predetermined scanning rate $\left(10^{\circ} \mathrm{C} / \mathrm{min}\right)$ and over a predetermined temperature range $30^{\circ} \mathrm{C}$ to $400^{\circ} \mathrm{C}$ in the presence of nitrogen flow at a rate of $40 \mathrm{ml} / \mathrm{min}$. Indium was checked by running the sample in triplicate, the standard deviations calculated were found negligible.

\section{X-ray diffraction}

The X-ray diffraction patterns of untreated $\mathrm{Tr} . \mathrm{HCl}$, the polymer (chitosan L*; \%DD 80-85), casted film of the drug with the polymer and its corresponding physical mixture.

\section{Scanning electron microscopic studies}

The surface morphology of the drug-dispersed films before and after 
drug release studies were examined. The test sample was attached to the metal stubs with double pressure sensitive adhesive tape and coated with thin layer of platinum to improve the conductivity. Scanning electron photomicrographs were taken at 15000-x magnification.

\section{Culture and in-vitro susceptibility test}

Determination of minimum inhibitory concentration (MIC) was performed by using the tube dilution technique as described by Shadomy and Espinel-Ingroff ${ }^{18}$. On the other hand, the sizes of the zones of inhibition were measured using the diffusion technique as described by Lorain $^{19}$.

Candida albicans was grown on sabaroud dextrose at $37^{\circ} \mathrm{C}$ for $24 \mathrm{hrs}$. This microorganism was inoculated onto the medium to give approximately $10^{6}$ cells $/ \mathrm{ml}$ for microorganism. The prepared suspension was diluted with sterile saline solution and adjusted to $\mathrm{pH}$ 6.5. Media growth is recorded after $24 \mathrm{hrs}$ incubation at $37^{\circ} \mathrm{C}$.

The lowest concentration of the drug in $\mu \mathrm{g} / \mathrm{ml}$ that prevents in-vitro growth was taken as the MIC. A control was done in parallel with the test for this sample. The mean of at least 3 readings was determined.

The prepared Tr.HCl: chitosan $\mathrm{L}^{*}$ films containing different drug concentrations $(1,1.2,1.4,1.6,1.8 \%$ Tr. $\mathrm{HCl}$ and 1.8. Tr.HCl\% w/w of polymer in the presence of GTA) was tested for antifungal activity against candida albicans. Also Tr.HCl normal dressing were prepared and subjected to the same test.

For inoculation of nutrient broth, a volume of $0.1 \mathrm{ml}$ of culture was placed onto the surface of sabaroud dextrose plate. Discs of Tr.HCl: chitosan $\mathrm{L}^{*}$ (different concentrations) films and normal dressing containing $1.8 \% \mathrm{w} / \mathrm{w}$ of terbinafine $\mathrm{HCl}$ were placed and gently pressed down on the surface of sabaroud dextrose fluid media. Plates were incubated for 24$48 \mathrm{hrs}$ at $37^{\circ} \mathrm{C}$ and zones of inhibition were measured.

\section{RESULTS AND DISCUSSIONS}

\section{Content uniformity}

Terbinafine $\mathrm{HCl}$ was extracted from different regions of chitosan film using Acetonitrile : ETOH (1:1) solvent system. After normalization of the amount of terbinafine $\mathrm{HCl}$ on weight basis of film, the results indicated that the variation in distribution of terbinafine $\mathrm{HCl}$ in different regions of film was $<13 \%$.

\section{Effect of drug loading on the release pattern from chitosan films}

The effect of different concentrations of terbinafine $\mathrm{HCl}$ $(1 \%, 1.2 \%, 1.4 \%, 1.6 \%$ and $1.8 \%$ $\mathrm{w} / \mathrm{w}$ of polymer) on the release rate of the drug from chitosan films was investigated.

The percentage of drug concentration were corresponding to $25,30,35,40$ and $45 \mathrm{mg} /$ film drug for the volume of the dissolution medium (phosphate buffer of $\mathrm{pH}=$ 6.8) was adjusted for each film to 
afford sink conditions and to obtain spectrophotometrically measurable sample for low drug concentration. The obtained results are listed in Tables $1 \& 2$ and Fig. 1.

The release rate constant of the drug increased as the concentration in the film increased. Straight line of high correlation coefficient ( $r=$ 0.999) was also obtained when the amount of the drug released was plotted against the square root of time (Fig. 1).

The release data of terbinafine $\mathrm{HCl}$ from chitosan films were analyzed according to zero-order, first order $^{20}$, and diffusion controlled release mechanisms according to the simplified Higuchi model ${ }^{21}$. The obtained results proved that the gradual increase in the drug loading caused a significant increase in the value of $t_{1 / 2}$ and the release of the drug from chitosan films followed Higuchi diffusion model (Tables 1 \& 2).

Kanke et $a l .^{22}$ reported that predinsolone was released from chitosan film following zero order wheras; Chandy, and Sharms ${ }^{23}$ reported first order kinetics. Puttipipatkhachorn et al. ${ }^{24}$ found that the release of salicylic acid from chitosan films obeyed Fickian diffusion control mechanism with subsequent zero-order.

Thacharodi and Panduranga Rao studied the diffusion behavior of some drugs through chitosan membranes; they evaluated the diffusion efficacy of chitosan films for both hydrophilic and hydrophobic drugs $^{25-27}$. The water-soluble drug (propranolol $\mathrm{HCl}$ ) could be transported through films via pore mechanism ${ }^{27}$; wheras the hydrophobic drug (nifedipine) could be influenced by both partition and pore mechanisms operating concurrently ${ }^{26 \& 27}$.

The increase in the release rate constant of a given drug increases upon increasing drug concentration in the film could be explained by assuming that matrix porosity necessary for the diffusion pathway may create pores by the dispersed drug. Increasing drug concentration in the film may result in increasing the degree of internal porosity ${ }^{28}$. Similar results were obtained in this study, where the release of $\mathrm{Tr} . \mathrm{HCl}$ from chitosan films was found to be through pores. Scanning electron microscopy photographs of the films further confirmed this after the drug release (Fig. 2).

\section{Effect of inclusion of different types of plasticizers on drug release pattern}

Five chitosan $\mathrm{L}^{*}$ films containing different plasticizers were prepared to investigate the effect of plasticizer nature on $\mathrm{Tr} . \mathrm{HCl}$ release. The concentration of each plasticizer was $20 \% \mathrm{w} / \mathrm{w}$ of polymer and each film containing $45 \mathrm{mg} \mathrm{Tr} . \mathrm{HCl}(1.8 \% \mathrm{w} / \mathrm{w}$ of polymer). The obtained results were listed in Tables $3 \& 4$ and graphically represented in Figure 3.

When the medicated plasticized chitosan films were immersed in phosphate buffer $(\mathrm{pH}=6.8)$, two factors could be taken into 
Table 1: Kinetic data of the drug released from chitosan $\mathrm{L}^{*}$ films at different concentrations of terbinafine $\mathrm{HCl}$.

\begin{tabular}{|c|c|c|c|c|c|c|}
\hline \multirow{2}{*}{\multicolumn{2}{|c|}{ Mechanism of Release }} & \multicolumn{5}{|c|}{$\begin{array}{l}\text { Drug concentration } \\
\% \text { w/w of polymer }\end{array}$} \\
\hline & & 1 & 1.2 & 1.4 & 1.6 & 1.8 \\
\hline \multirow{2}{*}{$\begin{array}{l}\text { First } \\
\text { order }\end{array}$} & $\mathrm{r}$ & 0.997 & 0.994 & 0.987 & 0.995 & 0.987 \\
\hline & $\mathrm{K}_{0}\left(\min ^{-1}\right)$ & 0.0009 & 0.0010 & 0.00093 & 0.0094 & 0.00088 \\
\hline \multirow{2}{*}{$\begin{array}{l}\text { Zero } \\
\text { order }\end{array}$} & $\mathrm{r}$ & 0.991 & 0.989 & 0.977 & 0.990 & 0.987 \\
\hline & $\mathrm{K}_{1}(\mathrm{mg} / \mathrm{min})$. & 0.0227 & 0.028 & 0.034 & 0.043 & 0.0507 \\
\hline \multirow{2}{*}{$\begin{array}{l}\text { Higuchi } \\
\text { diffusion }\end{array}$} & $\mathrm{r}$ & 0.999 & 0.999 & 0.995 & 0.998 & 0.998 \\
\hline & $\mathrm{K}_{\mathrm{h}}\left(\mathrm{mg} / \mathrm{cm}^{2} / \mathrm{min}^{1 / 2}\right)$ & 0.617 & 0.785 & 0.940 & 1.178 & 1.383 \\
\hline \multirow{2}{*}{$\begin{array}{l}\text { Log Q vs } \\
\log t\end{array}$} & $\mathrm{r}$ & 0.998 & 0.999 & 0.994 & 0.998 & 0.998 \\
\hline & Slope & 0.670 & 0.545 & 0.564 & 0.556 & 0.560 \\
\hline \multicolumn{2}{|c|}{ Best fit model } & Higuchi & Higuchi & Higuchi & Higuchi & Higuchi \\
\hline
\end{tabular}

$\mathrm{r}$ : Correlation coefficient

$\mathrm{K}_{0}$ :Zero order release rate constant

$\mathrm{K}_{1}$ : First order release rate constant

$\mathrm{K}_{\mathrm{h}}$ : Diffusion release rate constant

Table 2: Effect of drug concentration on release rate constant $(\mathrm{k})$, half-life $\left(\mathrm{t}_{1 / 2}\right)$ for chitosan $\mathrm{L}^{*}$ films containing different concentrations of terbinafine $\mathrm{HCl}$ according to Higuchi-diffusion model.

\begin{tabular}{|c|c|c|c|}
\hline $\begin{array}{c}\text { Drug concentration } \\
(\% \text { w/w of polymer })\end{array}$ & $\begin{array}{c}\text { Release rate } \\
\text { constant }(\mathrm{k})\end{array}$ & $\begin{array}{c}\text { Correlation } \\
\text { coefficient }(\mathrm{r})\end{array}$ & $\mathrm{t}_{1 / 2}$ (min.) \\
\hline 1 & 0.617 & 0.999 & 410.44 \\
\hline 1.2 & 0.785 & 0.999 & 365.12 \\
\hline 1.4 & 0.940 & 0.995 & 452.69 \\
\hline 1.6 & 1.178 & 0.998 & 450.39 \\
\hline 1.8 & 1.383 & 0.998 & 470.54 \\
\hline
\end{tabular}


Table 3: Kinetic data of the drug released from chitosan $L^{*}$ films at different types of plasticizers, each films containing 45 $\mathrm{mg}$ terbinafine $\mathrm{HCl}$.

\begin{tabular}{|c|c|c|c|c|c|c|c|}
\hline \multirow{2}{*}{\multicolumn{2}{|c|}{ Mechanism of Release }} & \multicolumn{6}{|c|}{ Plasticizers types } \\
\hline & & \multirow{2}{*}{$\begin{array}{l}\text { GTA } \\
0.992\end{array}$} & \multirow{2}{*}{$\begin{array}{c}\text { PEG400 } \\
0.994\end{array}$} & \multirow{2}{*}{$\begin{array}{c}\mathrm{PG} \\
0.999 \\
\end{array}$} & \multirow{2}{*}{$\begin{array}{c}\text { GTB } \\
0.995\end{array}$} & \multirow{2}{*}{$\begin{array}{c}\text { DMPH } \\
0.818\end{array}$} & \multirow{2}{*}{$\begin{array}{c}\text { DEPH } \\
0.995\end{array}$} \\
\hline & $\mathrm{R}$ & & & & & & \\
\hline First order & $\mathrm{K}_{0}\left(\min ^{-1}\right)$ & 0.002 & 0.001 & 0.006 & 0.002 & 0.001 & 0.001 \\
\hline \multirow{2}{*}{ Zero order } & $\mathrm{R}$ & 0.989 & 0.990 & 0.998 & 0.992 & 0.991 & 0.993 \\
\hline & $\mathrm{K}_{1}$ (mg/min.) & 0.0254 & 0.025 & 0.021 & 0.021 & 0.0197 & 0.0192 \\
\hline \multirow{2}{*}{$\begin{array}{l}\text { Higuchi } \\
\text { diffusion }\end{array}$} & $\mathrm{R}$ & 0.998 & 0.999 & 0.995 & 0.999 & 0.999 & 0.998 \\
\hline & $\mathrm{K}_{\mathrm{h}}\left(\mathrm{mg} / \mathrm{cm}^{2} / \mathrm{min}^{1 / 2}\right)$ & 0.690 & 0.666 & 0.541 & 0.588 & 5.35 & 0.514 \\
\hline \multirow{2}{*}{$\begin{array}{c}\text { Log Q vs } \\
\log \mathrm{t}\end{array}$} & $\mathrm{r}$ & 0.999 & 0.999 & 0.994 & 0.999 & 0.999 & 0.999 \\
\hline & Slope & 0.512 & 0.534 & 0.432 & 0.524 & 0.528 & 0.528 \\
\hline \multicolumn{2}{|c|}{ Best fit model } & Higuchi & Higuchi & Higuchi & Higuchi & Higuchi & Higuchi \\
\hline
\end{tabular}

$\mathrm{r}$ : Correlation coefficient

$\mathrm{K}_{1}$ : first order release rate constant
$\mathrm{K}_{0}:$ Zero order release rate constant

$\mathrm{K}_{\mathrm{h}}$ : Diffusion release rate constant 
Table 4: Effect of different plasticizers on release rate constant $(k)$, half-life $\left(t_{1 / 2}\right)$ for chitosan $\mathrm{L}^{*}$ films each containing $45 \mathrm{mg}$ terbinafine $\mathrm{HCl}$ according to Higuchi-diffusion model.

\begin{tabular}{|c|c|c|c|}
\hline Plasticizers & $\begin{array}{c}\text { Release rate constant }(\mathrm{k}) \\
\left(\mathrm{mg} / \mathrm{cm}^{2} / \mathrm{min}^{1 / 2}\right)\end{array}$ & $\begin{array}{c}\text { Correlation } \\
\text { coefficient }(\mathrm{r})\end{array}$ & $\mathrm{t}_{1 / 2}(\mathrm{~min})$. \\
\hline Plain & 1.0367 & 0.998 & 470.89 \\
\hline GTA & 0.6906 & 0.998 & 1063.56 \\
\hline PEG400 & 0.668 & 0.999 & 1134.63 \\
\hline PG & 0.541 & 0.995 & 1729.29 \\
\hline GTB & 0.534 & 0.999 & 1775.75 \\
\hline DEPH & 0.525 & 0.999 & 1836.42 \\
\hline DMPH & 0.519 & 0.998 & 1879.33 \\
\hline
\end{tabular}

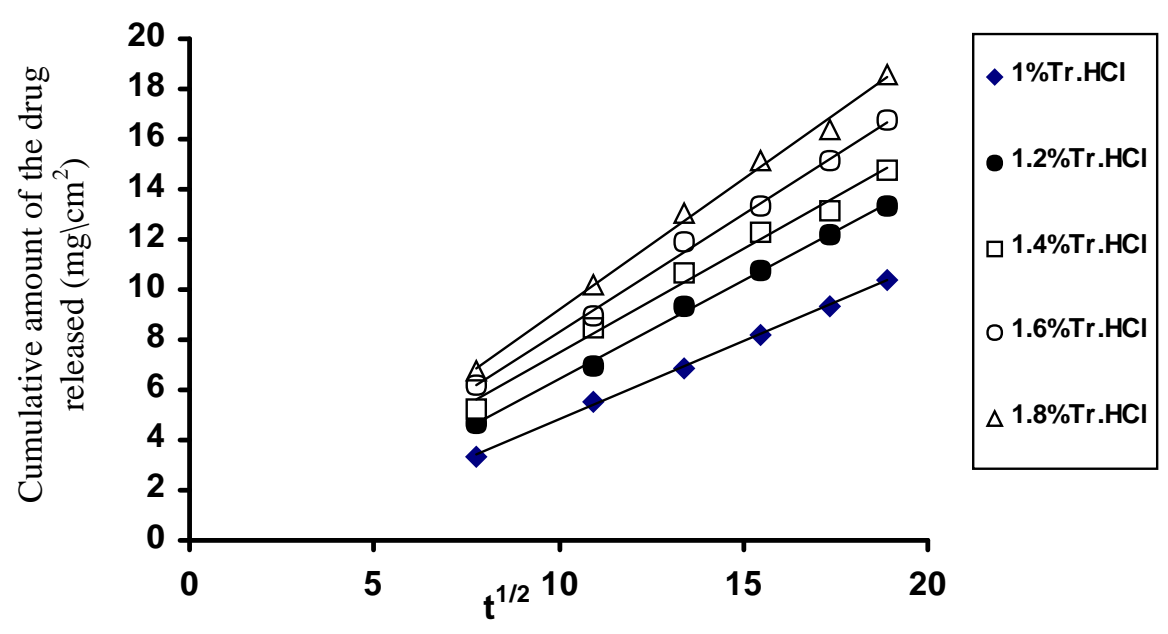

Fig. 1: Amount of drug released $\mathrm{mg} / \mathrm{cm}^{2}$ from chitosan $\mathrm{L} *$ films at different concentrations of terbinafine hydrochloride. 


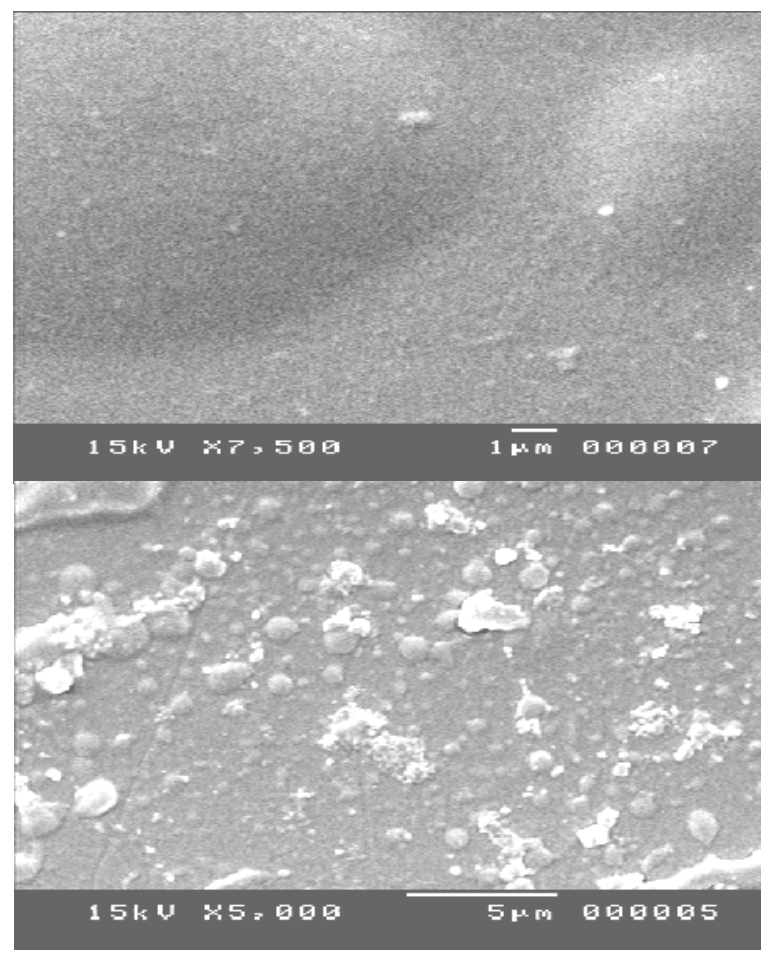

Fig. 2: Scanning electron micrographs of films containing $1.8 \% \mathrm{w} / \mathrm{w}$ terbinafine hydrochloride. A: Before release of the drug, b: After release of the drug.

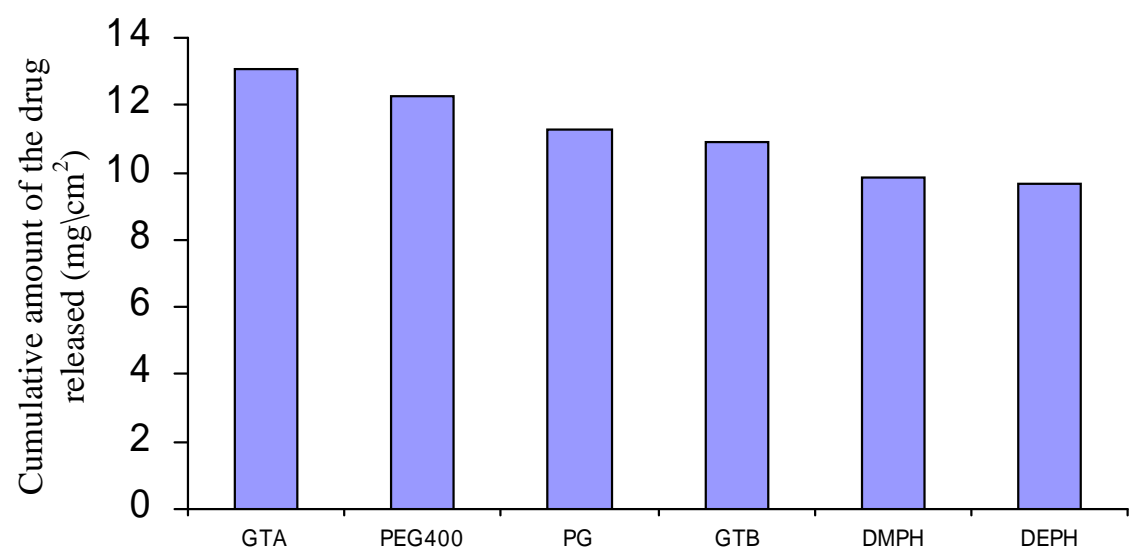

Fig. 3: Comparison of drug release profile for chitosan $\mathrm{L}^{*}$ films each containing $45 \mathrm{mg}$ terbinafine hydrochloride and plasticized with $20 \% \mathrm{w} / \mathrm{w}$ of polymer with different plasticizers after 6 hours. 
consideration to explain the effect of plasticizer content on drug release profile. The first is the solubility of the plasticizer in water (i.e. the probability of hydrogen bonding between the plasticizer and water molecules), while the second is the extent of channels or pathways through which the plasticizer will be leached throughout the polymeric matrix $^{29}$.

The obtained results showed that the effect of different plasticizers on the release rate of the drug from chitosan films can be arranged in the following order: GTA > PEG400 > PG $>$ GTB $>$ DMPH $>$ DEPH.

It is concluded that GTA, PEG400 and PG could be leached through a continuous hydrated capillary network of channels, which is a major characteristic feature for all tested water-soluble plasticizers. Also the hydrophilic nature or the solubility of the plasticizers in the release medium can be considered as an important factor in controlling this process. Dimethyl phthalate (DMPH), diethyl phthalate (DEPH), and glycerol tributyrate (GTB) were investigated in this study as examples for waterinsoluble plasticizers. Upon diffusion of the film, Tr.HCl would diffuse through the hydrated voids created by those water-insoluble plasticizers. This may explain the release of small amount of Tr. $\mathrm{HCl}$ from chitosan films plasticized with water-insoluble plasticizers compared to those plasticized with water-soluble plasticizers.

\section{IR spectroscopy}

Infrared spectra of chitosan powder, terbinafine $\mathrm{HCl}$, and films were recorded to get information about interactions between the drug and the polymeric carriers in the solid state. The transmission spectra of chitosan powder exhibited broad peaks in the range from 3520 to 3445 $\mathrm{cm}^{-1}$ (Fig. 4a), which were assigned to $\mathrm{OH}$ stretching, indicating intermolecular hydrogen bonding of chitosan molecules. An overlap was seen in the same region of $\mathrm{NH}$ stretching. The $\mathrm{C}=\mathrm{O}$ stretching (amid I) peak near $1650 \mathrm{~cm}^{-1}$ and $\mathrm{NH}$ bending (amid II) peak near 1556 $\mathrm{cm}^{-1}$ regions were observed in the spectra of the chitosan grades $\mathrm{L}^{*}$ representing the structure of $\mathrm{N}$-acetyl glucose amine ${ }^{30}$.

The principal peaks of terbinafine $\mathrm{HCl}$ appear at $3300 \mathrm{~cm}^{-1}\left(\mathrm{~N}-\mathrm{CH}_{3}\right)$ (Fig. 4b). The peak remained visible upon combination with the polymer and showed no discernable shifts or broading. Thus, from IR spectral analysis, there is no change in the location or width of the infrared absorption bands of the drug and chitosan either in the physical mixture or in the medicated chitosan films. Therefore, it might be concluded that there was no interactions between the drug and the polymer used.

\section{Differential scanning calorimetry (DSC)}

In order to shed some light on the possibility of solid state changes, DSC was carried out for the untreated drug, chitosan L*, 80-85\% DD alone, drug: chitosan $L^{*}$ physical mixtures, 


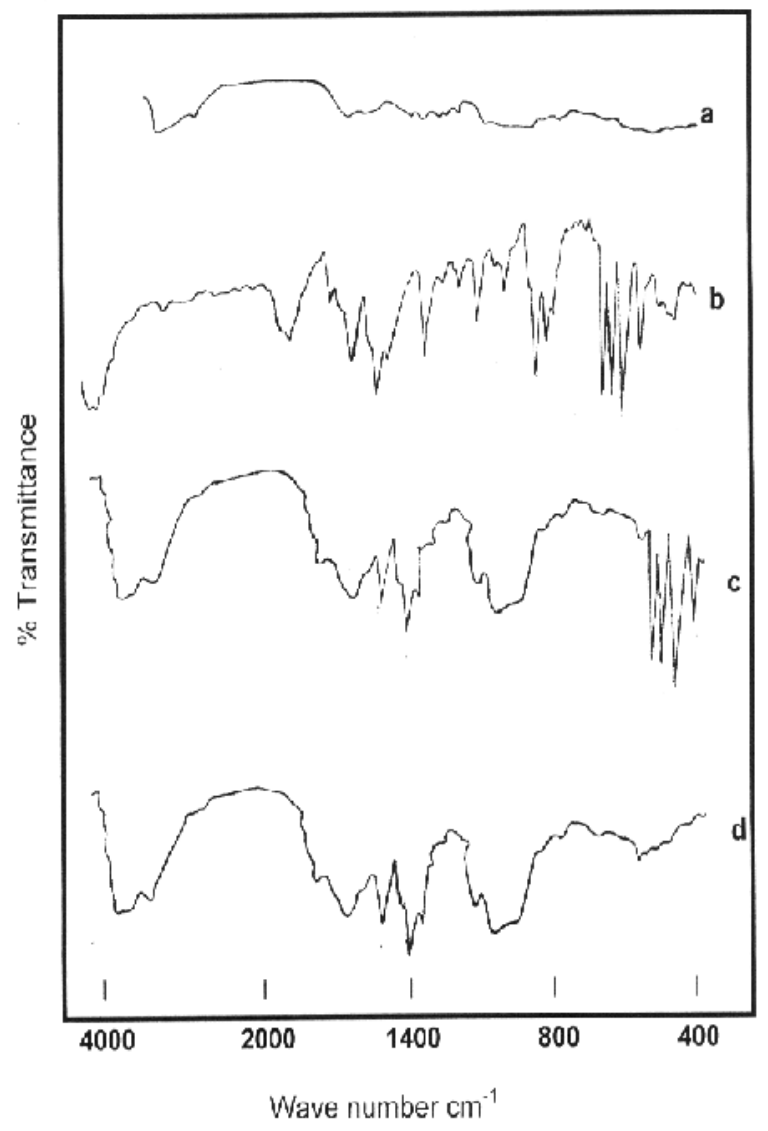

Fig. 4: IR spectra of a: chitosan $L^{*}$ powder, b: drug alone powder, c: physical mixture of Tr.HCl-chitosan $\mathrm{L}^{*}$ and $\mathbf{d}$ : cast film of Tr.HCl-chitosan $\mathrm{L}^{*}$.

and the corresponding medicated films.

Figure $5 \mathrm{~b}$ shows the DSC curve of terbinafine $\mathrm{HCl}$ that shows a single melting endothermic peak, melting point at $176.54^{\circ} \mathrm{C}$ and $\Delta \mathrm{H}=-28.64$ $\mathrm{Kcal} / \mathrm{Kg}$.

Chitosan L*; $80-85 \%$ DD free film, as reported in the literature ${ }^{31}$, show no melting endothermic peaks. The thermograms of physical mixtures show the same drug characteristic with minor changes.

Differential Scanning Calorimetry scans of the drug incorporated into the polymer showed no characteristic peaks of the drug. The disappearance of the drug peaks at $1.8 \% \mathrm{w} / \mathrm{w}$ of polymer $\mathrm{Tr} . \mathrm{HCl}$ polymeric film is related to the drug in the cast films present in the amorphous form or in the extremely fine crystallites of molecular dispersion, which could not 


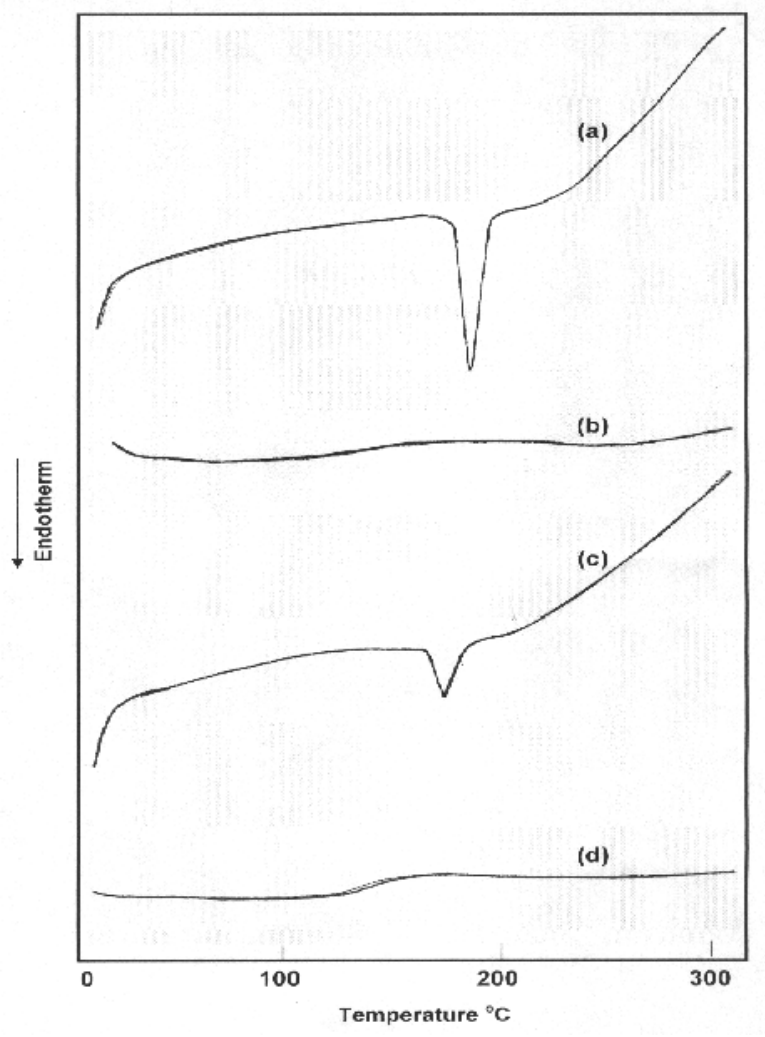

Fig. 5: DSC thermograms of a: drug alone, b: chitosan $L^{*}$ powder, c: physical mixture of Tr.HCl-chitosan $\mathrm{L}^{*}$ and $\mathbf{d}$ : cast film of Tr.HCl-chitosan $\mathrm{L}^{*}$.

detected by DSC. Similar findings were obtained by Kodha et al. ${ }^{32}$ who noticed the disappearance of endothermic peak of Lidocaine $\mathrm{HCl}$ in the solid dispersion films containing hydroxy propyl cellulose (HPC). They explained this phenomenon on the bases that complete transformation of the drug from crystalline to amorphous form when incorporated into the polymer.

\section{X-ray diffractometry}

To get further evidence on the solid state changes, X-ray diffraction spectra were carried out for untreated drug, medicated chitosan $L^{*}$ films $(1.8 \% \mathrm{w} / \mathrm{w}$ of polymer of $\mathrm{Tr} . \mathrm{HCl})$ and their physical mixtures as well as individual components.

The pattern of Tr.HCl (Fig. 6b) alone shows the presence of numerous distinct peaks indicating that, the drug is present as crystalline form with characteristic diffraction peaks appearing at $2 \theta$ of $6.81,15.70$, 20.29 and 25.57 degree, which were selected for comparative purposes.

On the other hand, chitosan L*, $\%$ DD 80-85 polymer didn't show any 


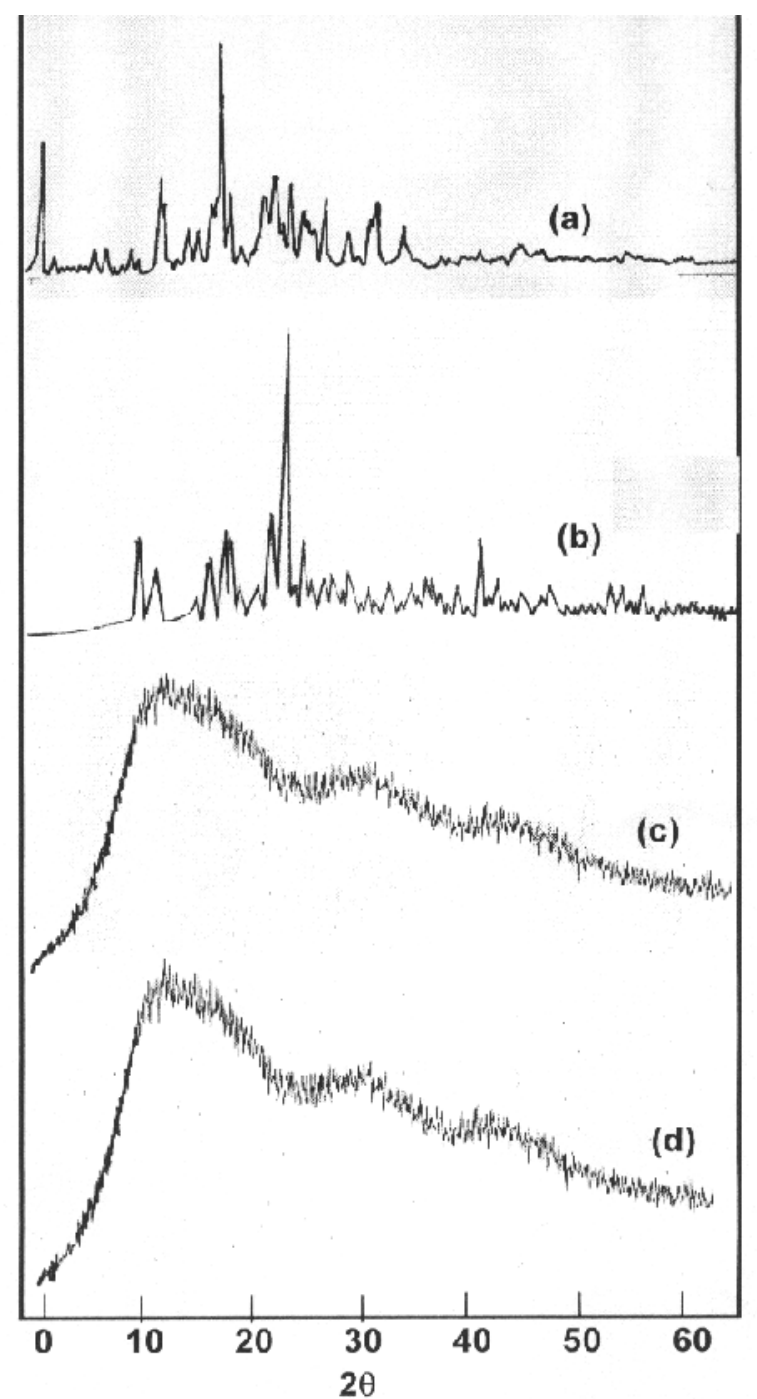

Fig. 6: X-ray pattern of a: drug alone, b: chitosan $L^{*}$ powder, c: physical mixture of Tr.HCl-chitosan $\mathrm{L}^{*}$ and $\mathbf{d}$ : cast film of Tr.HCl-chitosan $\mathrm{L}^{*}$.

diffraction peaks indicating its amorphous nature (Fig. 6a). The diffraction patterns of cast films formed from $\mathrm{Tr} . \mathrm{HCl}$ with chitosan $\mathrm{L}^{*}$ polymer are characterized by complete absence of the drug characteristic peaks and conversion to the amorphous form. These findings comply with the data obtained by differential scanning calorimetry where the melting endothermic peaks of drug are absent in the cast film. 
These results are in agreement with Kodha et al. ${ }^{32}$ who reported the disappearance of $\mathrm{X}$-ray diffraction peaks of drug crystals in the Lidocaine-EC-HPC solid dispersion film.

\section{Antifungal activity of terbinafine HCl polymeric films}

The minimum inhibitory concentration (MIC) of Tr.HCl against candida albicans is found to be $1.4 \mu \mathrm{g} / \mathrm{ml}$. Thus, it can be concluded that this microorganisms was susceptible to Tr.HCl.

The antimicrobial effect of chitosan in the form of film is due to the structural modification of chitosan to chitosanium acetate resulting in a cross-linking between the polycation in chitosonium acetate and the anions on the surface of microorganisms which altered the membrane permeability, thereby resulting in a leakage of glucose and lactate dehydrognose from its cell. This is in agreement with earlier mechanism by Tasi and $\mathrm{Su}^{33}$ underlying the inhibitory activity of shrimp chitosan (98\% DD) against Escherechia coli.

Also, Senel et al. ${ }^{7}$ founded that chitosan gel was less active than chlorhexidine gluconate solution against candida albicans and the highest antifungal activity obtained with $2 \%$ chitosan gel containing $0.1 \%$ chlorhexidine.
A Quantitative comparative study of the antifungal activity of medicated films with normal dressing, each containing the same concentrations of Tr.HCl, was performed and the results were shown in Table 5 and Fig. 7. It was found that medicated chitosan $\mathrm{L}^{*}$ films showed a higher response in the inhibition zone than normal dressing.

The size of inhibition zones for medicated chitosan $\mathrm{L}^{*}$ films at different drug concentrations showed a dramatic increase in the inhibition zone sizes with increasing drug concentration (Table 5).

The incorporation of $(10 \% \mathrm{w} / \mathrm{w}$ of polymer) GTA into medicated chitosan $L^{*}$ films, resulted in higher response in the inhibition zone sizes for the drug. The inhibition zone sizes reflected quantitative concentration gradient established by diffusion of the drug through a given medium and the susceptibility of the tested microorganism (Fig. 8).

The obtained results revealed that the benefit of chitosan $L^{*} 80-85 \%$ DD as film former and delivery for antifungal drug, and it was recommended to use medicated chitosan $\mathrm{L}^{*}$ films for topical treatment of fungal infections. 


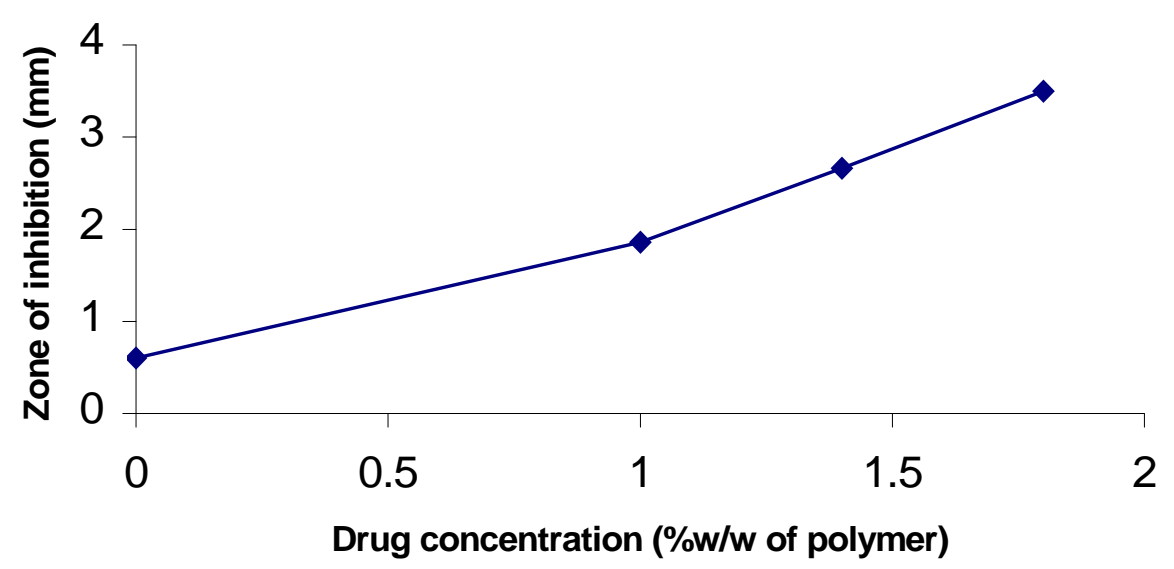

Fig. 7: Antifungal activity of medicated chitosan L* films at different drug concentrations.

Table 5: Antifungal efficacy of medicated chitosan $\mathrm{L}^{*}$ films against Candida Albican at different drug concentrations.

\begin{tabular}{|c|c|}
\hline Drug concentration & Zone of inhibition (diameter in $\mathrm{cm}$ ) \\
\hline Plain (o drug) & 0.6 \\
\hline 1 & 1.86 \\
\hline 1.4 & 2.66 \\
\hline 1.8 & 3.5 \\
\hline Normal dressing & 3.25 \\
\hline Plasticized film & 6.30 \\
\hline
\end{tabular}




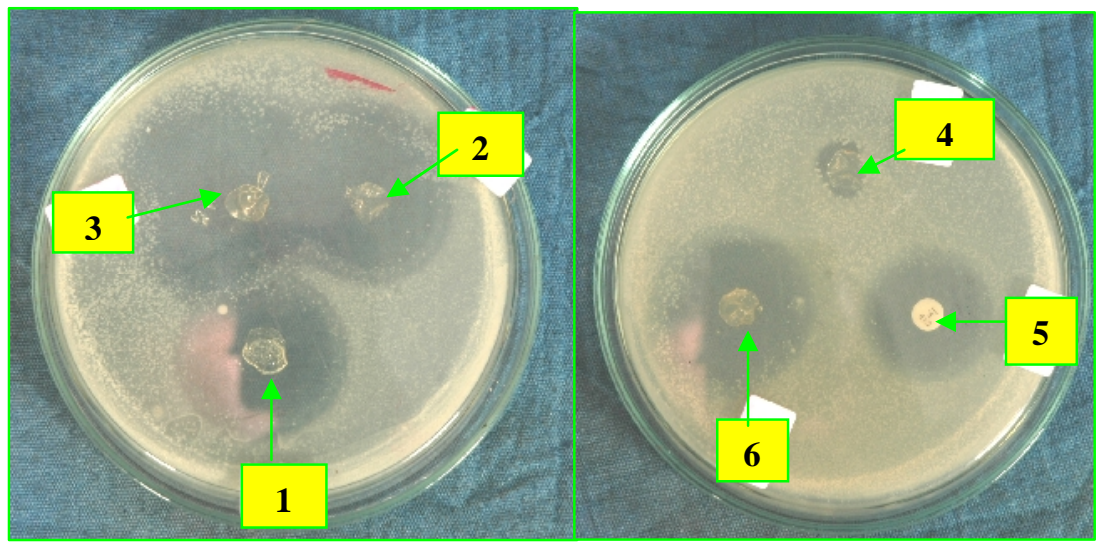

Fig. 8: Photographs represent the antifungal activity of different terbinafine. $\mathrm{HCl}$ formulations against Candida albicans.

$110 \% \mathrm{w} / \mathrm{v}$ chitosan film containing $1 \% \mathrm{w} / \mathrm{w}$ terbinafine. $\mathrm{HCl}$.

$210 \% \mathrm{w} / \mathrm{v}$ chitosan film containing $1.4 \% \mathrm{w} / \mathrm{w}$ terbinafine. $\mathrm{HCl}$.

$310 \% \mathrm{w} / \mathrm{v}$ chitosan film containing $1.8 \% \mathrm{w} / \mathrm{w}$ terbinafine. $\mathrm{HCl}$

4 Non-medicated chitosan film $(10 \% \mathrm{w} / \mathrm{w})$.

5 Normal dressing $(1.8 \% \mathrm{w} / \mathrm{w})$.

6 Plasticized chitosan film $(1.8 \% \mathrm{w} / \mathrm{w})$.

\section{REFERENCES}

1. N. Angeiova and D. H, Trends Biotechnol., 17, 409, 1999.

2. O. Pillai and R. Panchagnula, Curr. Opin. Chembiol., 5, 447, 2001.

3. Sh. Pangbum, PV. Trescony and G. Heller, Biomaterials, 3, 105, 1982.

4. I. B. Tsvetkova, L. M. Bronstein, S. N. Sidorov, O. L. Lependina, M. G. Sulman, P. M. Valetsky, B. Stein, L. Zh. Nikoshvili, V. G. Matveeva, A. I. Sidorov, B. B. Tikhonov, G. N. Demidenko, L.
Kiwi-Minsker and E. M. Sulman, J. Molec. Cat., 276, 116, 2007.

5- N. Boucard, C. Viton, D. Agay, E. Mari, T. Roger, Y. Chancerelle and A. Domard, Biomaterials, 28, 3478, 2007.

6- P. C. Srinivasa, M. N. Ramesh and R. N. Tharanathan, Food Hydrocolloid, 21, 1113, 2007.

7- S. Senel, G. Ikinci and S. Kas, Int. J. Pharm., 193, 197, 2000.

8- J. Zan, D. Zhu, F. Tan, G. Jiang, Y. Lin and F. Ding, Chin. J. Chem. Engin., 14, 235, 2006.

9- Sr. Jameela and A. Jayakrinan, Biomaterials, 16,769, 1995. 
10- Md. Blanco, C. Gomez and R. Olmo, Int. J. Pharm., 202, 29, 2000.

11- A. Miwa, A. Ishiba and M. Nakano, Pharm. Res., 15, 1844, 1998.

12- J. Ma, H. Wang and B. Ha, Biomaterials, 22, 331, 2001.

13- S. Miyazaki, H. Yamaguchi and M. Takada, Acta Pharm. Nord., 2, 401, 1990.

14- B. Anand Babu and P. Ramesh, J. Pharm. Sci., 6, 1208, 2004.

15- C. Dollery in "Theraputic Drugs", Churchill Livingstone, New York, $2^{\text {nd }}$ Ed., 1999, 2, pp. t41-t44.

16- D. Thacharodi and K. Panduranga Rao, Int. J. Pharm., 96, 33, 1993.

17- J. Sciara, and S. P. Patel, J. Pharm. Sci., 10, 65, 1976.

18- S. Shadomy and A. EspinelInrraff. in: "Manual of Clinical Microbiology", Washington, D.C., U.S.A. $3^{\text {rd }}$ Ed., 1980, pp. 647-653.

19- V. Lorain, in "Antibiotics in Laboratory Medicine", Baltimore USA $2^{\text {nd }}$ Ed., 1986, p. 428.

20- A. Martin, J. Swarbrick, and A. Cammarata, in "Physical Pharmacy", Lea and Febiger, $2^{\text {nd }}$ Ed., 1983, pp. 358-359.

21- W. I. Higuchi, J. Pharm. Sci., 51, 802, 1962.
22- M. Kanke, H. Katayama, S. Tsuzuki and H. Kuramoto, Chem. Pharm. Bull., 37, 523, 1989.

23- T. Chandy, and C. P. Sharma, Biomat. Art. Cells Immob. Biotech., 19, 745, 1991.

24- S. Puttipipatkhachorn, J. Nunthanid, K. Yamamoto, and G. E. Peck. J. Control. Release, 75, 143, 2001.

25- D. Thacharodi, and $\mathrm{K}$. Panduranga Rao, J. Chem Tech. Biotechnol., 58, 177, 1993.

26- D. Thacharodi, and K. Panduranga Rao, Int. J. Pharm., 96, 33, 1993.

27- D. Thacharodi, and K. Panduranga Rao, Biomaterials, 17, 1307, 1996.

28- S. Shin, and S. Cho, Drug Dev. Ind. Pharm., 22, 299, 1996.

29- A. Ismail, M. G. Abd El Mohsen, and H. A. El-Ghamry, Zgazig J. Pharm. Sci., 7, 111, 1998.

30- T. Imai, S. Shiarishi, H. Saito and M. Otagiri, Int. J. Pharm., $67,11,1991$

31- J. Nunthanid, S. Puttipiptkhachorn, K. Yamamoto, and G. E. Peck, Drug Dev. Ind. Pharm., 27, 143, 2001.

32- Y. Kodha, H. Kobayashi, Y. Baba and H. Yuasa, Int. J. Pharm., 158, 147, 1997.

33- G. J. Tsai. and W. H. Su, J. Food Port, 62, 239, 1999. 